Classification

Physics Abstracts

$61.70 \mathrm{~W}-68.48-78.70 \mathrm{D}-73.40 \mathrm{~L}-68.22$

\title{
Spectrum-Line Profile Analysis of a Magnesium Aluminate Spinel/ Sapphire Interface
}

\author{
John Bruley, Ming-Wei Tseng and David B. Williams
}

Whitaker Laboratory 5 packes Av., Department of Materials Science and Engineering, Lehigh University, Bethlehem, Pa 18017

(Received November 16, 1994; accepted February 10, 1995)

\begin{abstract}
Spatially resolved chemical composition and spectroscopic line profiles have been gathered from the space charge region across a spinel/sapphire interface using a dedicated scanning transmission electron microscope. The electron energy-loss spectra reveal an excess of $\mathrm{Mg}$ (relative to stoichiometric spinel) along with $\mathrm{Cr}$ segregated to the interfacial zone. A quantitative least squares decomposition of a spectrum-line profile of the $\mathrm{Al} L_{2,3}$ absorption edge fine structures into two standard components clearly highlights the transition from sapphire into spinel; further analysis indicates that the degree of site inversion, which is the fractional occupancy of tetrahedral sites by trivalent $\mathrm{Al}$, increases within $5 \mathrm{~nm}$ of the boundary. The overall charge neutrality at the interface is maintained by the increased concentration of negative charge, probably interstitial $\mathrm{O}$ anions which are also present in excess quantity relative to stoichiometric spinel and sapphire.
\end{abstract}

\section{Introduction}

The transient liquid phase bonding of a Haynes 230 nickel based superalloy and sapphire fiber composite, processed at a temperature of $1200^{\circ} \mathrm{C}$ and a pressure of $14 \mathrm{MPa}$, results in significant interfacial chemical reaction between the components. The high temperature creep and fracture properties of such composites are strongly influenced by the product phases and their interfaces to both the ceramic and metal matrix [1-5]. To aid future material development, characterization of these interfacial regions is therefore considered important. Trace amounts of magnesium dissolved in an alloy will react with the sapphire to form a stoichiometric magnesium aluminate spinel phase [6-8]; and this is observed in the aforementioned composite. In the vicinity of the spinel/sapphire interface the environment will deviate substantially from bulk equilibrium values due to the build up of charged defects and segregation of impurities which occurs during nucleation and growth [9]. It is upon this boundary which we have chosen to focus our attention, using the spectrum-line profile technique of spatially resolved electron energy-loss spectroscopy (SREELS).

The nature of the interface between sapphire $\left(\alpha-\mathrm{Al}_{2} \mathrm{O}_{3}\right)$ and spinel $\left(\mathrm{MgO} \cdot \mathrm{nAl}_{2} \mathrm{O}_{3}\right)$ is of gen- 
eral interest because of its widespread occurrence in many structural materials systems. Through changes in its stoichiometry and exchange in cation sites, spinel is able to accommodate rather large concentrations of charged point defects. This is in contrast to $\alpha-\mathrm{Al}_{2} \mathrm{O}_{3}$, whose defect structure is mostly extrinsic. Atomic transport and interface energy are clearly related to defect chemistry but a correlation between the detailed atomic structure, the chemical bonding, the stoichiometry, cation disorder, and impurity solute segregation is still poorly understood because of the difficulty of getting informative data. Chiang and co-workers $[10,11]$ have shown there to be a strong influence of chemical composition and space charge on the grain boundary mobility of magnesium aluminate spinels during heat treatments and a number of groups (for example [3, 12-19]) have paid attention to elucidating the detailed atomic structures at various ceramic-oxide interfaces and grain boundaries. In particular, Li et al. [20] have recently described the atomic structure of the magnesium aluminate/sapphire boundary formed between a $\mathrm{MgO} / \mathrm{Al}_{2} \mathrm{O}_{3}$ couple by a solid state interdiffusion process that had been activated by the irradiation of the electron microscope. To date, there has not been much work focused on determining the chemical and electronic properties of these interfaces at (or near) the atomic level [21, 22].

The current studies were conducted to examine the extent to which SREELS can be used to map point defect distributions. We investigate whether the technique can be used to extract the degree of inversion of a spinel and to what extent this information can be used to map the site occupancy across the spinel/sapphire boundary. The preliminary assessment is carried out with the $\mathrm{Al} L_{2,3}$ absorption edge recorded from a series of spinel standards, selected for their known range of tetrahedral and octahedral occupancies. The same data analysis is applied to standard spectra as to those acquired in a linescan across the heterophase interface.

\section{Background}

2.1 CRystal Structures AND Point Defects. - The crystal structure of spinel is cubic $\left(a_{0}=0.808 \mathrm{~nm}\right)$ with a unit cell containing a close packed array of 32 oxygen anions or 8 formula units. In normal spinel one half of the 32 six-fold coordination interstices (the B or octahedral sites), are occupied by trivalent $\mathrm{Al}$ cations and 8 of the four-fold coordination positions (the $\mathrm{A}$ or tetrahedral sites) are occupied by divalent $\mathrm{Mg}$ cations. At elevated temperatures the cations may exchange sites, leading to partially inverse spinel. The degree of cation inversion, $i$, is defined as the fraction of tetrahedral sites occupied by the trivalent $\mathrm{Al}$. For natural spinels this fraction is small $(<0.05[23,24])$ since they have cooled and equilibrated over geological time-scales. An inversion parameter of 1 corresponds to inverse spinel, where substitution of half of the $\mathrm{Al}$ ions with the $\mathrm{Mg}$ ions occurs. A statistically random distribution of cations leads to an inversion parameter of two thirds. Synthetic spinels held at room temperature have been reported to exhibit $i$ ranging between 0.1 and 0.3 [23-30]. There has been a great deal of discussion over the space group of spinel, namely whether it is Fd3m or F $\overline{4} 3 \mathrm{~m}$ [29-33]. The controversy concerns small cation displacements which remove the center of inversion at the B-sites. Since any cation displacements are expected to be rather small they will have, at most, a rather modest effect on the chemical bonding and therefore the electron energy-loss spectra. No further attention is paid to this issue here.

The solubility of $\mathrm{Al}_{2} \mathrm{O}_{3}$ in spinel increases as temperature rises over about $1000{ }^{\circ} \mathrm{C}$ [34]. Dissolution of $\mathrm{Al}_{2} \mathrm{O}_{3}$ leads to significant non-stoichiometry with $\mathrm{Al}^{3+}$ cations occupying tetrahedral sites (designated as $\mathrm{Al}_{\mathrm{Mg}}^{\bullet}$ in Kroger-Vink notation [35]). In the bulk, the excess unit positive charge of each trivalent cation occupying a bivalent site is compensated by the accompanying formation of a suitable number of negatively charged cation vacancies which may be either on octahedral $\left(V_{\mathrm{Al}}^{\prime \prime \prime}\right.$, with a formal net charge of 3-) or tetrahedral sites $\left(V_{\mathrm{Mg}}^{\prime \prime}\right.$, with formal net charge of 2-). From 
NMR measurements, it was concluded that the vacancies predominantly occupy the octahedral B sites even though there is only a very slight difference in energy between the two possibilities [36]. There is also a strong possibility of significant ordering of the cation vacancies, evidenced by calorimetric measurements $[24,26]$. Concerning the presence of cation interstitial defects, unpublished calculations by Mackrodt (reported in Ref. [11]) indicate that formation energies are high $(3-6 \mathrm{eV})$ so that there will be insignificant concentrations of these defects under standard temperatures and pressures. In contrast to the solubility of $\mathrm{Al}_{2} \mathrm{O}_{3}$, there is only moderate solubility of $\mathrm{MgO}$ into spinel even at high temperatures. In this case, accommodation of the excess negative charge of bivalent $\mathrm{Mg}$ occupying octahedral sites $\left(\mathrm{Mg}_{\mathrm{Al}}^{\prime}\right)$ is accomplished either by creation of $\mathrm{O}$ vacancies $\left(V_{\mathrm{O}}^{\bullet \bullet}\right)$ or cation interstitials $\left(\mathrm{Mg}_{\mathrm{i}}^{\bullet \bullet}\right.$ or $\left.\mathrm{Al}_{\mathrm{i}}^{\bullet \bullet \bullet}\right)$.

Sapphire (or $\alpha-\mathrm{Al}_{2} \mathrm{O}_{3}$ ) possesses the corundum structure, being composed of an hexagonal close packed array of oxygen ions, with trivalent $\mathrm{Al}$ cations occupying two thirds of the available octahedral sites between the basal planes. The very high vacancy and interstitial formation energies of $\alpha-\mathrm{Al}_{2} \mathrm{O}_{3}$ result in very low point defect concentrations at standard temperatures [37].

The composition and structure of $\mathrm{Al}_{2} \mathrm{O}_{3}$ surfaces and interfaces have been the topic of numerous studies and are found to be strongly dependent upon the ambient environment $[3,16,38-45]$. In conditions of high oxygen partial pressure, most surfaces are believed to be oxygen terminated. When bonded directly to a metal, the oxygen can form direct localized metal-oxide bonds and, if present as excess charge ionic defects, they can lead to electrostatic-images in the metal which generate attractive forces [46, 47]. The growth of an ionic spinel in the presence of the electrostatic potential of such interface charge will most likely generate a space charge region dependent upon the nucleation conditions.

2.2 Electron SPeCtroscopic Characterization of SPINELS. - Previous electron energyloss studies of mineral standards led to the identification of characteristic $\mathrm{Al}$ and $\mathrm{Mg}-\mathrm{K}$ near-edge structures as chemical fingerprints of octahedral and tetrahedral coordination [48]. This concept has been extensively developed by Brydson and others in the characterization of $\mathrm{Al}$ and $\mathrm{Si}$ oxides [49-55]. The site occupancy of spinel was investigated by making use of electron channeling and off-axis collection to increase site-selection specificity of the energy-loss signal [56-59]. These experiments all used broad beam techniques and, therefore, are difficult to apply to interfaces.

Atom location by channeling enhanced microanalysis using X-ray spectroscopy has likewise been used to characterize normal and inverse spinels, although again without high spatial resolution [60]. Typically three atoms, one of known site occupancy, are required to identify site inversion. A recent application to magnesium aluminate spinel using the $\mathrm{O}, \mathrm{Mg}$ and $\mathrm{Al}$ signals is described by Qian et al. [59, 61]. It is also possible, in theory, to distinguish inverse from normal spinel by quantitative analysis and refinement of diffraction patterns. In practice however, the scattering power of $\mathrm{Al}$ and $\mathrm{Mg}$ are similar, making it rather difficult. A spatially resolved series of electron nanodiffraction patterns across a spinel/MgO interface was presented though no details of inversion were investigated at that time [62].

The current work relies heavily on the premise that the local symmetry and nearest neighbor coordination dominates the $\mathrm{Al} L_{2,3}$ energy-loss near edge fine structure (ELNES). In the small angle or dipole limit, the $L_{2,3}$ ELNES corresponds to transitions of bound electrons from innershell p orbitals into vacant states of s- and d-like symmetry. Brydson and co-workers have studied the edge structures of numerous minerals where the cation sites are believed to be well known [49-54]. From these systematic studies "fingerprints "were identified for 6-fold, 5-fold and 4-fold coordination of $\mathrm{Al}$ and $\mathrm{Si}$ each surrounded by $\mathrm{O}$ (the electronic structures of $\mathrm{Al}, \mathrm{Mg}$, and $\mathrm{Si}$ oxides are all very similar). Real-space multiple scattering calculations to simulate edge shapes for single shell clusters provides a reasonable agreement between the theory and experiment. 6-fold coordination is marked by an intense, relatively sharp peak at onset consisting primarily of $\mathrm{Al} \mathrm{s}$ 
states whereas 4-fold coordination gives rise to a much broader resonance. If the chemical bonding in spinel was localized to nearest neighbor interactions only, the mixed coordination exhibited by partially inverse spinels would be expected to yield a doublet edge structure. Recently, Tanaka et al. [63] performed a first principles discrete variational $\mathrm{X} \alpha$ molecular orbital calculation of a small cluster of $\mathrm{SiO}_{2}$ involving a central tetrahedrally coordinated $\mathrm{Si}$ ion surrounded by 4 similarly coordinated tetrahedra. Results suggest that whilst the first coordination shell (i.e. $\mathrm{Si}-\mathrm{O}_{4}$ ) dominates the structure, next-nearest neighbor interactions do introduce neighboring cation site band hybridization which broadens and lifts state degeneracies in the conduction bands, thereby explaining the multiplicity of peaks in the edge structure. Other electron structure calculations have been carried out for $\mathrm{MgAl}_{2} \mathrm{O}_{4}$ [64] and $\mathrm{Al}_{2} \mathrm{O}_{3}$ [64-69], and for molecules and small clusters [70-73]. However, symmetry and site projections of the density of states are either not yet available or do not provide a good fit to the data. An added complication to the interpretation of the near edge structure of oxides is the relatively strong many electron core-hole excitonic interaction. This removes the translational symmetry at the central atom and makes a one-to-one correspondence between one-electron band structure and the experimental near edge structure rather unlikely $[74,75]$. For the purpose of the current study however, localization brought about by the tightly bound exciton probably enhances the sought after site selectivity.

\section{Methods}

3.1 THE SPINEL/SAPPHIRE INTERFACE. - During of the transient liquid bonding process of a Haynes 230 nickel based superalloy matrix-sapphire fiber composite, micron sized stoichiometric spinel protrusions were formed over a large fraction of the sapphire fiber surfaces. One such protrusion is illustrated in Figure 1. The fabrication process was carried out at $1200{ }^{\circ} \mathrm{C}$, under a pressure of $14 \mathrm{MPa}$ for 2 hours. Whilst Haynes 230 and its additives contains a wide range of elements, including $\mathrm{Ni}, \mathrm{Cr}, \mathrm{W}, \mathrm{Mo}, \mathrm{Co}, \mathrm{Fe}, \mathrm{C}, \mathrm{Si}, \mathrm{La}, \mathrm{B}, \mathrm{Mn}, \mathrm{Mg}$ and $\mathrm{Cu}$ only $\mathrm{Mg}, \mathrm{Al}, \mathrm{Cr}$ and $\mathrm{O}$ were observed within these spinel zones and there was no evidence for preferential segregation of other impurities to the spinel/fiber interface. The typical sensitivity limit of the EDX spectroscopy surveying technique used is estimated to be about 0.5 at.\% for most elements. A more complete account of the chemistry of this complex metal/ceramic composite system is given in a Ph. D. Thesis by one of these authors (M.W.T.). Here we are concerned only with the nature of the magnesium aluminate spinel and its interface to the sapphire substrate. The sample was prepared for TEM observation using standard techniques of mechanical grinding followed by ion-milling.

3.2 STANDARDS. - To examine the effects of defects and cation inversions on the near edge structures, two natural spinel crystals, one synthetic stoichiometric $\left(\mathrm{MgO} \cdot \mathrm{Al}_{2} \mathrm{O}_{3}\right)$ and one synthetic non-stoichiometric $\left(\mathrm{MgO} .2 \mathrm{Al}_{2} \mathrm{O}_{3}\right)$ magnesium aluminate crystals, and a $\gamma-\mathrm{Al}_{2} \mathrm{O}_{3}$ sample were studied. All standards were examined in powdered form, prepared by crushing small pieces of the spinel into a suspension of acetone and collecting on a lacy carbon film. In the microscope, only thin areas of crystal suspended over holes in the support were studied.

3.3 MiCROSCOPY. - The samples were examined in a V.G. Microscopes' HB501 dedicated scanning transmission electron microscope operating at $100 \mathrm{keV}$. The spectra were acquired with a Gatan model 666 parallel electron energy loss spectrometer, controlled by a Mac II computer running Gatan's proprietary EL/P software. The conditions for collecting the $\mathrm{Mg}$ and $\mathrm{Al} L_{2,3}$ and the $\mathrm{O} \mathrm{K}$ edges were such that the beam semi-angle incident on the sample was about $8 \mathrm{mrad}$ and the spectrometer collection semi-angle was about $16 \mathrm{mrad}$. This provided an incident probe-size of about $1 \mathrm{~nm}$ and a beam current of about $0.3 \mathrm{nA}$. For the $\mathrm{Mg}$ and $\mathrm{Al} \mathrm{K}$ edges, the incident beam 


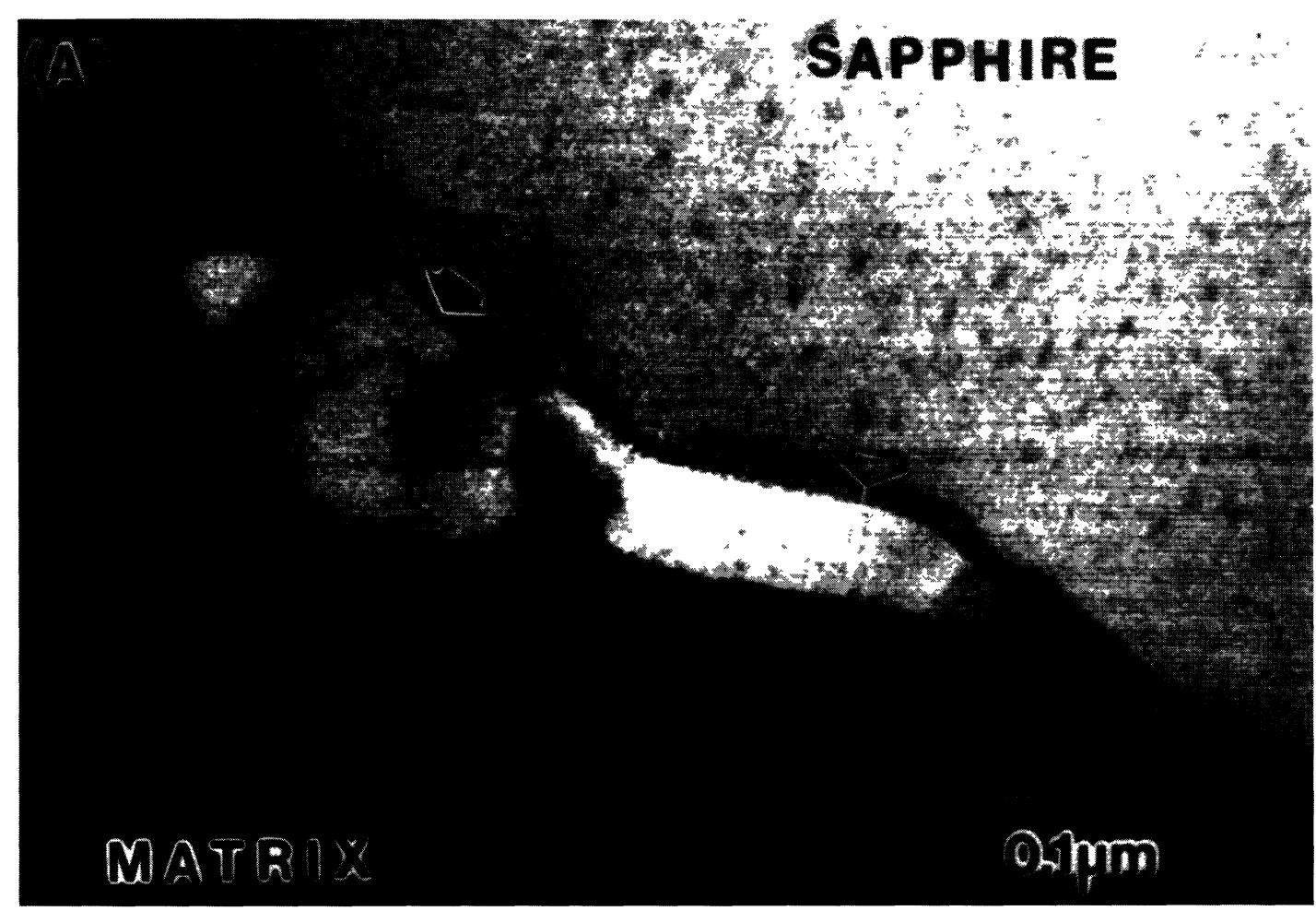

Fig. 1. - Low magnification bright field image of the spinel protrusion resulting from reaction during the transient liquid phase bonding of Haynes 230 superalloy/sapphire fiber composite. Back area in bottom left corner is due poor electron transmission through the significant mass thickness of the metal matrix.

and collection semi-angles were increased to 16 and $32 \mathrm{mrad}$, respectively, and the beam current was increased to about $1 \mathrm{nA}$. The probe size on the sample in this instance was of the order of several nanometers. The stoichiometry of the bulk spinel phases were measured using the $\mathrm{O}, \mathrm{Al}$ and $\mathrm{Mg} \mathrm{K}$ edges. Since this did not require high spatial resolution, the beam was scanned over an $100 \mathrm{~nm}^{2}$. area to minimize the possibility of artifacts due to beam damage. The measured intensity ratios were converted to atomic ratios using the hydrogenic cross-sections, available within EL/P. The results are tabulated in Table I.

Spectrum-line profiles were made with the aid of a custom function written for EL/P by Duscher, of the Max-Planck-Institut für Metallforschung in Stuttgart. Using this function, a series of spectra can be acquired with the electron beam scanning across the interface. The spectra are stored directly to the computer memory. The speed of the electron beam crossing the interface was controlled using the microscope's time base. Both the number of spectra and the read-out time per spectrum were adjusted so that the total acquisition time matched the time taken for the beam to scan across the microscope screen which was usually set to be $80 \mathrm{~s}$. The distance traveled by the beam is controlled by the microscope magnification. At 10 million times magnification the width of the full screen corresponds to about $13 \mathrm{~nm}$. The individual spectra in the series can be subsequently analyzed using conventional data analysis routines. The accumulation time for each spectrum was typically $3 \mathrm{~s}$ with approximately 10 thousand counts per readout. Each spectrum in the profiles presented here corresponds to a lateral pixel size of $0.5 \mathrm{~nm}$, which is smaller than the 
Table I. - Cation composition of spinels measured by EELS.

\begin{tabular}{|l|l|}
\hline Spinel & Mg/Al \\
\hline Natural & $0.48 \pm 0.04$ \\
(Mayfield) & \\
Natural (Burma) & $0.50 \pm 0.05$ \\
Synthetic (Union & $0.40 \pm 0.04$ \\
Carbide) & \\
Synthetic & $0.23 \pm 0.02$ \\
(MgO.2Al $\left.2 \mathrm{O}_{3}\right)$ & \\
Protrusion & $0.43 \pm 0.04$ \\
\hline
\end{tabular}

beam size.

Apart from the removal of the photodiode dark-current, data processing was accomplished by importing the spectral data into IGOR, a graphics and curve fitting program. Processing of the $\mathrm{Al}-L_{2,3}$ edge (edge threshold at $78 \mathrm{eV}$ ) involved background removal, which in the spinel phase was made difficult by the overlap of the broad $\mathrm{Mg} L_{2,3}$ edge d-shell resonance at $75 \mathrm{eV}$. To overcome this problem, the background was modeled by a power law, $A * E^{-r}$, superimposed with a Gaussian peak of half width of $10 \mathrm{eV}$, centered at $75 \mathrm{eV}$. The peak intensity of the Gaussian was found to be about $10 \%$ of the smooth power law in this region.

Each of the $L_{2,3}$ edges recorded in the spectrum-line profile line across the heterophase interface was separated by multiple least squares (MLS) decomposition into two standard components. The standards were assigned to be the two end members of the spectrum profile, which represent the edge shapes for spinel and sapphire. A similar MLS decomposition was done on the O-K edge profile. The mole-fraction of each componant was calculated on the assumption that the integrated partial cross section for the characteristic spinel edge-shape was the same as the sapphire edge-shape and that the total edge intensity was normalized to unity. Spectral intensity variations resulting from sample thickness changes across the boundary and beam current fluctuations were therefore ignored. Further processing of the $\mathrm{Al} L_{2,3}$ edge was accomplished by fitting two Gaussian peaks separated by about $2 \mathrm{eV}$ to the 2 initial edge threshold features. This is more clearly illustrated and discussed in the next section.

\section{Results}

In Figures $2 \mathrm{a}$ and $2 \mathrm{~b}$ the $\mathrm{Al}$ and $\mathrm{Mg} L$ edges of the spinel phase recorded within the bulk of the spinel product are illustrated. The $\mathrm{Al} L_{2,3}$ edge of sapphire is also shown in Figure $2 \mathrm{a}$ and it is obviously distinct from the spinel phase. Comparison of the spinel data in Figure 2 with the $\mathrm{Al} L$ edge spectra from natural spinel and non-stoichiometric spinel, contained in Figure 3, confirms a broad similarity in both the numbers and the positions of peaks but there are differences in relative intensities. This distinction is especially evident at the edge threshold where the intensity of peak-a is much weaker in the natural spinel. The ratio of peak-a to peak-b is conjectured to be proportional to the degree of inversion. To test this hypothesis the edge structures of the set of spinel standards, known to have different degrees of inversion, were analyzed by fitting two 
Gaussians of variable height and width to the peaks a and b within $4 \mathrm{eV}$ of threshold. An example of this two-Gaussian fit to natural spinel is displayed in Figure 3.
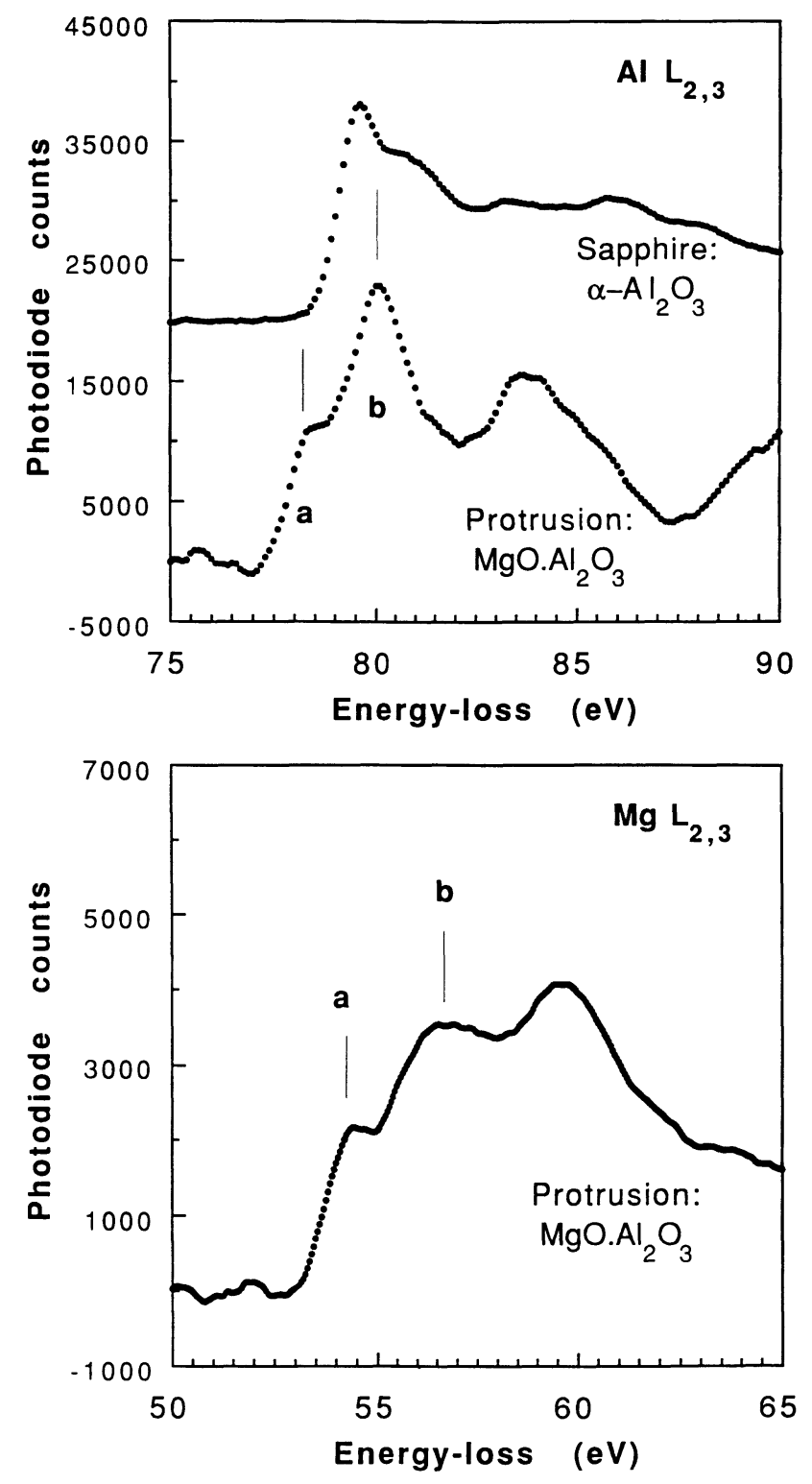

Fig. 2. - a) Near edge structures in the $\mathrm{Al} L_{2,3}$ spectra recorded on the bulk of the spinel protrusion after background removal and the sapphire fiber. b) The $\operatorname{Mg} L_{2,3}$ edge of the spinel phase.

There is some uncertainty concerning the actual amount of inversion in various spinels. However the data in column 2 of Table II attempts to summarize the anticipated degree of inversion occupancies of the normal, partially inverse and the non-stoichiometric spinels extracted from previously published data. Whilst there may be a large margin of error associated with these fig- 

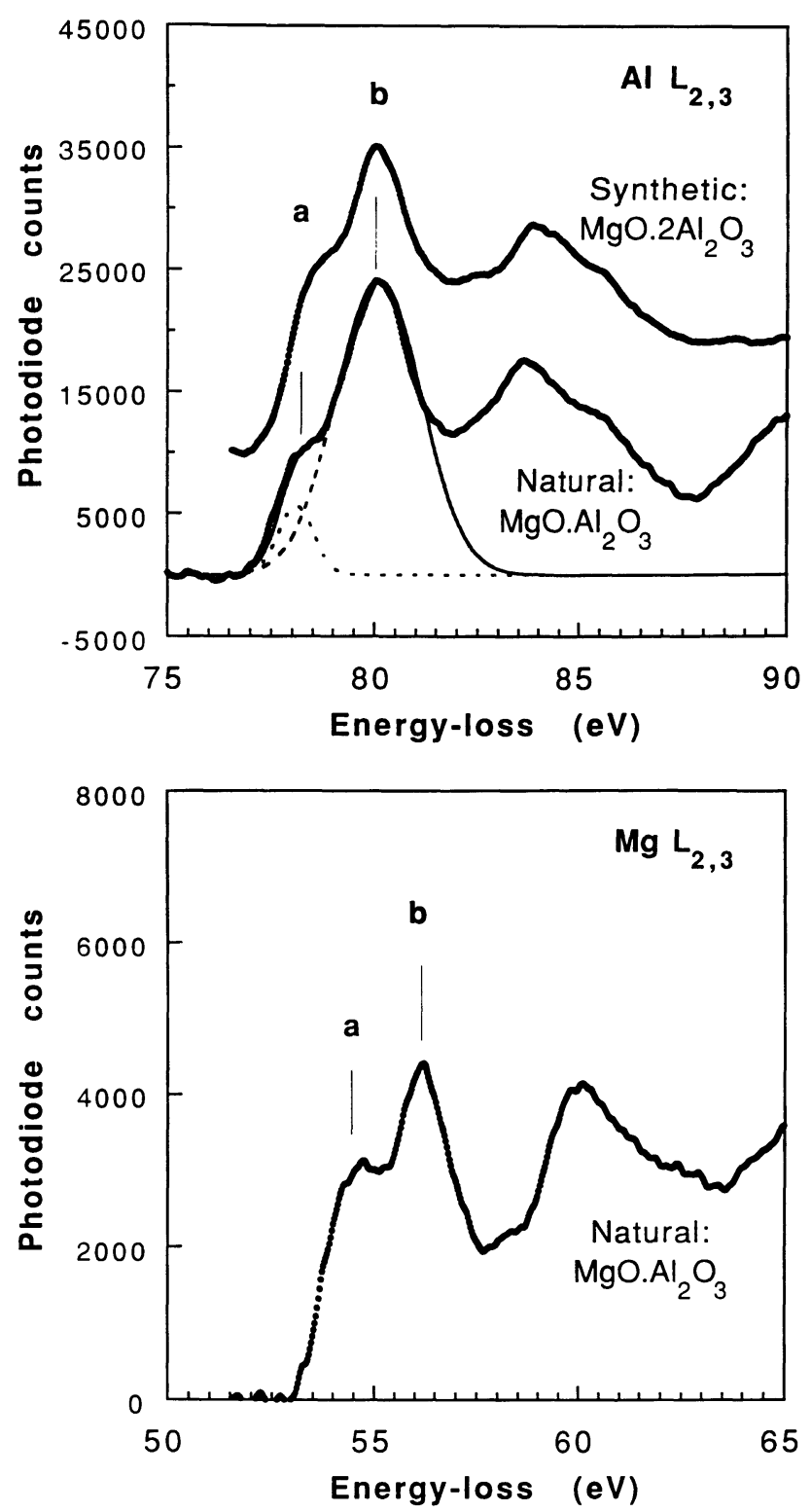

Fig. 3. - a) Near edge structures of the $\mathrm{Al} L_{2,3}$ spectra of natural spinel (Mayfield) and non-stoichiometric spinel $\left(\mathrm{MgO}^{2} 2 \mathrm{Al}_{2} \mathrm{O}_{3}\right)$. b) The $\mathrm{Mg} L_{2,3}$ edge of natural spinel.

ures the relative trend should be correct. The results of the peak-a to peak-b intensity ratios, $I_{\mathrm{a}} / I_{\mathrm{b}}$, are given in Table II and plotted against the expected inversion parameter for the standard spinel, show in Figure 4. The dashed line is the linear regression fit to the data and gives $\left(I_{\mathrm{a}} / I_{\mathrm{b}}\right)_{\text {meas. }}=0.52 i+0.14$. To draw the solid line it was assumed that the ratio varied linearly between the extrema of normal and inverse spinel. These end points were determined as follows: Instead of the nominal inversion of 0.05 (given in Tab. II), the assumption is made that natural spinel is perfectly normal, i.e. the $\mathrm{Mg}$ ions occupy only tetrahedral sites, and $\mathrm{Al}$ ions only octahedral sites. Accordingly, the $\operatorname{Mg} L_{2,3}$ edge shape and its experimental $I_{\mathrm{a}} / I_{\mathrm{b}}$ ratio which is found to 
be equal to 0.64 , represents $100 \%$ tetrahedral occupancy and the $I_{\mathrm{a}} / I_{\mathrm{b}}$ value for the $\mathrm{Al} L_{2,3}$ edge (equal to 0.08 ) represents $100 \%$ octahedral occupancy. Two observations are made: The first concerns the smail but finite intensity of peak-a in natural spinel despite a presumed inversion parameter close to zero. We note this peak is absent in $\alpha-\mathrm{Al}_{2} \mathrm{O}_{3}$. A likely explanation for this stems from orbital overlap of an octahedral $\mathrm{Al}$ site with neighboring tetrahedral cation sites (in normal spinel there are 6 tetrahedrally bound $\mathrm{Mg}$ ions at a distance of $0.33 \mathrm{~nm}$ ). Another reason may lie in a modification in the symmetry defined selection rules or in excitonic interactions in spinel with respect to corundum. The second observation concerns the slope of the fit. If the proposed simple model correlating bimodal site occupancy with electronic state density were correct, one might have expected the extreme limits of the peak intensity ratio to be set by the atomic fraction of $\mathrm{Al}$ on tetrahedral sites. In stoichiometric spinel an inverse parameter, $i$, equal to 1 corresponds to an atomic fraction on tetrahedral sites of $1 / 2$ and the ratio $\left(I_{\mathrm{a}} / I_{\mathrm{b}}\right)_{\text {meas. }}$ should thus vary according the relationship $\left(I_{\mathrm{a}} / I_{\mathrm{b}}\right)_{\text {meas. }}=0.56 i / 2+0.08$ and not $\left(I_{\mathrm{a}} / I_{\mathrm{b}}\right)_{\text {meas. }}=0.56 i+0.08$ as shown by the solid line in Figure 4. A reason for this discrepancy may again lie in next-nearest neighbor interactions, or be due to ordered clustering of point defects which affect the local density of states. A full explanation awaits simulation of these edge structures in normal and defect spinels. For the present, we ignore these distinctions and assume the empirical linear proportionality from normal to inverse spinel.

Table II. - Expected inversion parameters for standard spinels.

\begin{tabular}{|l|l|l|}
\hline Spinel & $\begin{array}{l}\text { Nominal } \\
\text { Inversion } \\
\text { Parameter, } \mathrm{i}\end{array}$ & $\mathbf{I}_{\mathbf{A}} / \mathbf{I}_{\mathbf{B}}$ \\
\hline $\begin{array}{l}\text { Natural } \\
\text { (Mayfield) } \\
\text { Natural } \\
(\text { Burma) } \\
\text { Synthetic }(\mathrm{Union}\end{array}$ & $0.05-0.10[28]$ & $0.084 \pm 0.003$ \\
$\begin{array}{l}\left.\text { Carbide, } \mathrm{MgO}^{\mathrm{Al}}{ }_{2} \mathrm{O}_{3}\right) \\
\text { Synthetic }\end{array}$ & $0.05-0.10[28]$ & $0.25 \pm 0.05$ \\
$\left(\begin{array}{l}\left.\mathrm{MgO}^{2} \mathrm{Al}_{2} \mathrm{O}_{3}\right) \\
\gamma-\mathrm{Al}_{2} \mathrm{O}_{3}\end{array}\right.$ & $0.25[36]$ & $0.32 \pm 0.08$ \\
\hline
\end{tabular}

The $\mathrm{O} \mathrm{K}$-edge, at $530 \mathrm{eV}$, also exhibits near edge structures characteristic of either spinel or sapphire. Figure 5 shows the two edge shapes recorded in bulk regions of the spinel and fiber. Detailed examination of the edge at $570 \mathrm{eV}$ indicates the presence of a small concentration of dissolved $\mathrm{Cr}$ in the spinel, which is clearly resolved in the difference spectrum. Magnesium chromate spinel forms a complete solid solution with magnesium aluminate spinel. The $\mathrm{Mg}$ and $\mathrm{Al}$ $\mathrm{K}$-edges (not shown) were recorded in the bulk spinel phase and confirmed the stoichiometry of the spinel. These edges also have characteristic near-edge structures which could be useful for electron structure analysis across interfaces. So far no such analysis has been carried out. 


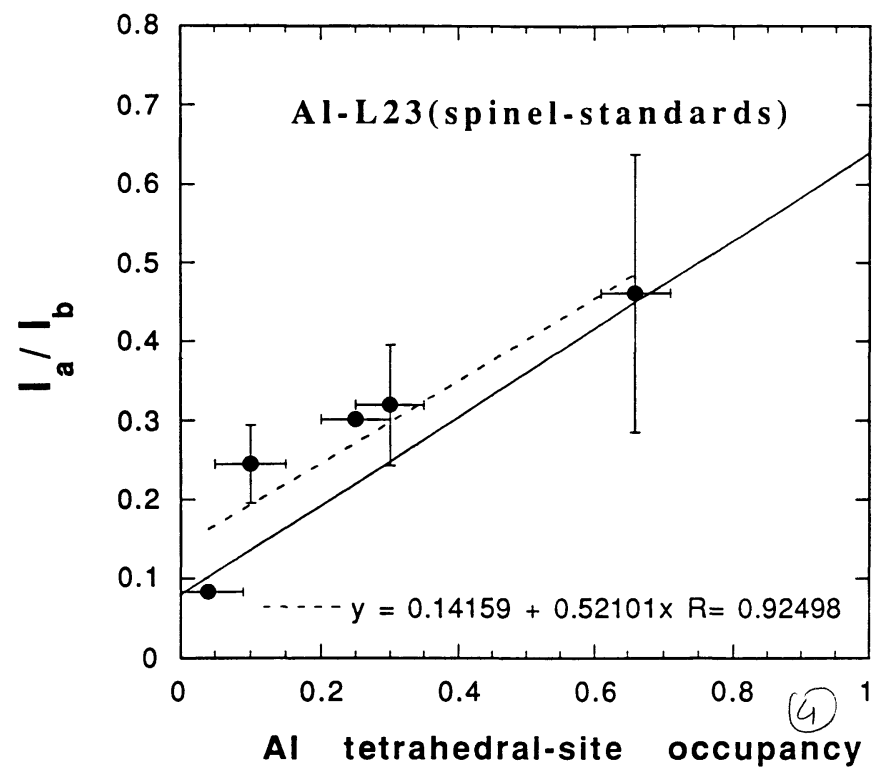

Fig. 4. - A plot of the experimental ratio $I_{\mathrm{a}} / I_{\mathrm{b}}$, extracted by fitting two Gaussian peaks to the edge threshold region of the $\mathrm{Al} L_{2,3}$. The abscissa represents the expected inversion parameter for the spinel standards examined.

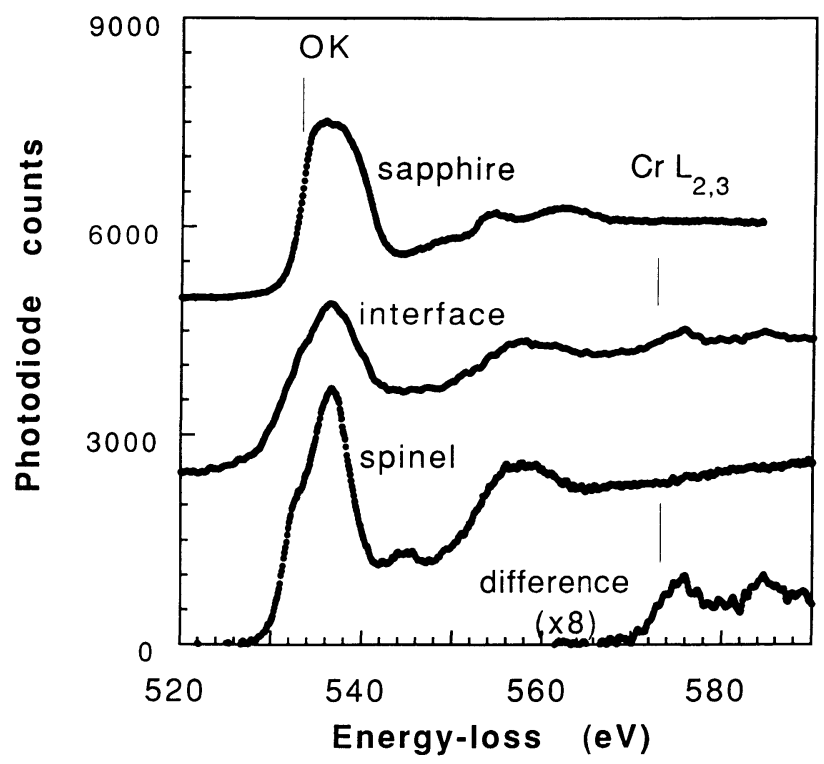

Fig. 5. - The oxygen K-edge from spinel protrusion, sapphire fiber and interface region. The difference between the spinel and interface spectra reveals the $\operatorname{Cr} L_{2,3}$ edge.

The $\mathrm{Al} L_{2,3}$ spectrum-line profile across the interface is shown in Figure 6 . The transition from sapphire into spinel occurs over a $5 \mathrm{~nm}$ region. Using the end members of this series as 
the principal components, the MLS decomposition provides spinel and sapphire mole fraction profiles. These are shown in the lower window of Figure 7, and are superimposed with the profiles obtained by similar decomposition of the characteristic O-K edges.

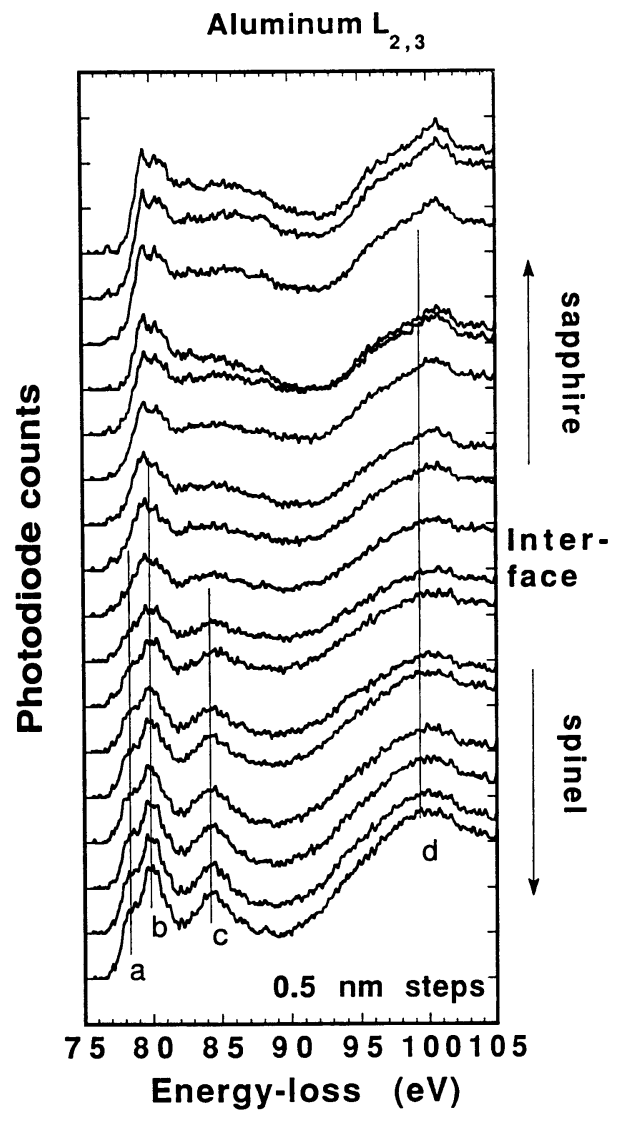

Fig. 6. - Individual spectra extracted from the spectrum-line profile measured across the spinel/sapphire interface recorded at $0.5 \mathrm{~nm}$ steps (consecutive spectra vertically off set for viewing purposes).

Composition profiles across the spinel/sapphire interface were generated from the spectrumline profiles by integrating the $\mathrm{Cr}, \mathrm{Mg}$ and $\mathrm{Al} L_{2,3}$, and $\mathrm{O} \mathrm{K}$ edge intensities. These profiles are shown in Figure 7. The $\mathrm{Cr} / \mathrm{Al}$ and $\mathrm{Mg} / \mathrm{Al}$ ratios indicate segregation of $\mathrm{Cr}$ and a slight increase in $\mathrm{Mg}$ relative to $\mathrm{Al}$ at the spinel/sapphire interface. The driving force for $\mathrm{Cr}$ segregation is presumably through atomic size misfit strain energy contributions. Increased free volume at the interface will yield preferred segregation. The increase in $\mathrm{Mg}$ at a distance $z$ from the interface, $\Delta(\mathrm{Mg} / \mathrm{Al})_{z}$ is most clearly evident when the mole fraction of spinel, $\chi_{\text {spin }}$ (derived by the MLS fitting of standard edge), normalized to the value of $(\mathrm{Mg} / \mathrm{Al})_{z}$ within the stoichiometric spinel, is subtracted,

$$
\Delta\left(\frac{\mathrm{Mg}}{\mathrm{Al}}\right)_{z}=\left(\frac{\mathrm{Mg}}{\mathrm{Al}}\right)_{z}-\frac{\chi_{\text {spin }}}{2}(z) .
$$

The signal $\Delta(\mathrm{Mg} / \mathrm{Al})_{z}$, labeled as excess $\mathrm{Mg}$ in Figure 7 , corresponds to the amount of Mg ex- 


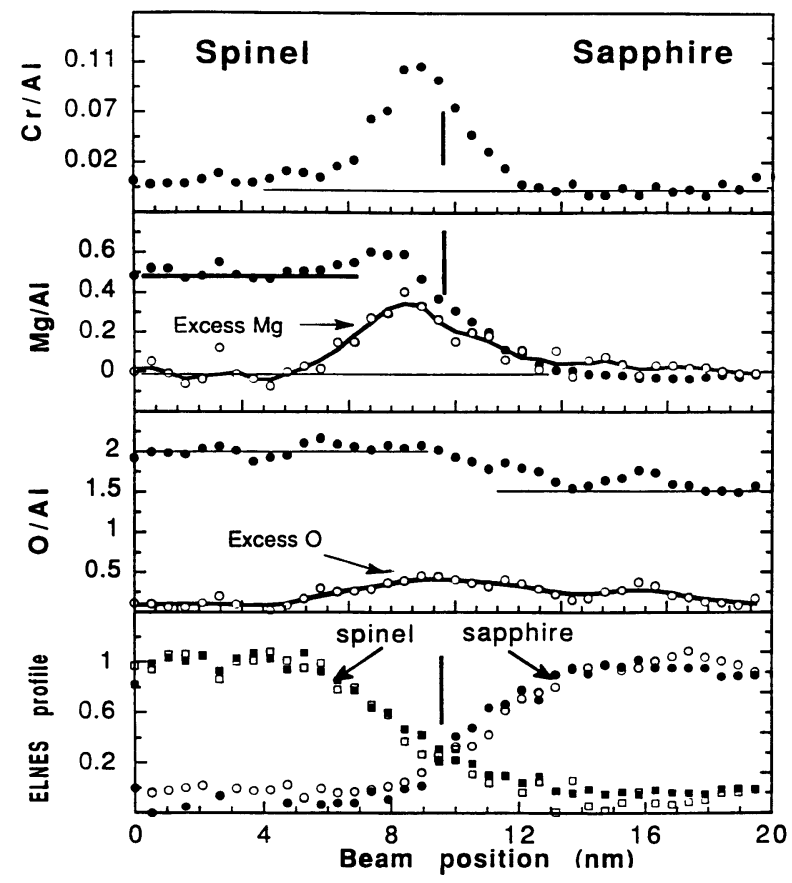

Fig. 7. - Line profiles of $\mathrm{Cr} / \mathrm{Al}$ (upper window), $\mathrm{Mg} / \mathrm{Al}$ (2nd window), $\mathrm{O} / \mathrm{Al}$ (3rd window), and mole fractions determined by MLS decomposition to $\mathrm{O}$ and $\mathrm{Al}$ edges (lower window). The excess curves, derived according to manner described in the text, illustrate segregation of $\mathrm{Mg}$ and $\mathrm{O}$ relative to the average stoichiometric background.

ceeding that expected for $\mathrm{MgO} \cdot \mathrm{Al}_{2} \mathrm{O}_{3}$ stoichiometric spinel and assumes there is little overlap with the neighboring sapphire crystal. After similar normalization on either side of the boundary, subtraction of the mole fraction profiles of spinel and sapphire from the $O$ signal reveals the excess amount of oxygen relative to the two standard oxides, i.e.

$$
\Delta\left(\frac{\mathrm{O}}{\mathrm{Al}}\right)_{z}=\left(\frac{\mathrm{O}}{\mathrm{Al}}\right)_{z}-2 \chi_{\mathrm{spin}}(z)-\frac{3 \chi_{\mathrm{sapp}}}{2}(z) .
$$

Inspection of the individual $\mathrm{Al}$ spectra close to the interface in Figure 6 gives the impression that the intensity ratio $\left(I_{\mathrm{a}} / I_{\mathrm{b}}\right)$ increases at the interface then drops to zero in the sapphire. This view is validated by the quantitative fitting of two Gaussians to the edge structures. The line profile of $\left(I_{\mathrm{a}} / I_{\mathrm{b}}\right)_{z}$ is plotted in Figure 8 . The curve labeled as $\left(I_{\mathrm{a}} / I_{\mathrm{b}}\right)^{*}$ was derived by subtracting from the profile the spinel mole fraction, normalized to the average ratio in the bulk spinel region, $\left(I_{\mathrm{a}} / I_{\mathrm{b}}\right)_{\text {spin }}$, i.e.

$$
\left(\frac{I_{\mathrm{a}}}{I_{\mathrm{b}}}\right)_{z}^{*}=\left(\frac{I_{\mathrm{a}}}{I_{\mathrm{b}}}\right)_{z}-\left(\frac{I_{\mathrm{a}}}{I_{\mathrm{b}}}\right)_{\text {spin }} \chi_{\text {spin }}(z) .
$$

As with the excess $\mathrm{Mg}$ signal, this represents an increase in $\left(I_{\mathrm{a}} / I_{\mathrm{b}}\right)$ relative to the nearby spinel phase. Taking $\left(I_{\mathrm{a}} / I_{\mathrm{b}}\right)$ as a measure of the site inversion, the profiles provide a vivid picture of the $\mathrm{Al}$ site inversion.

The Gaussian fit analysis also indicates that the half width of peak-a increases at the interface. This presumably reflects the considerable lattice distortion and therefore band broadening at the 


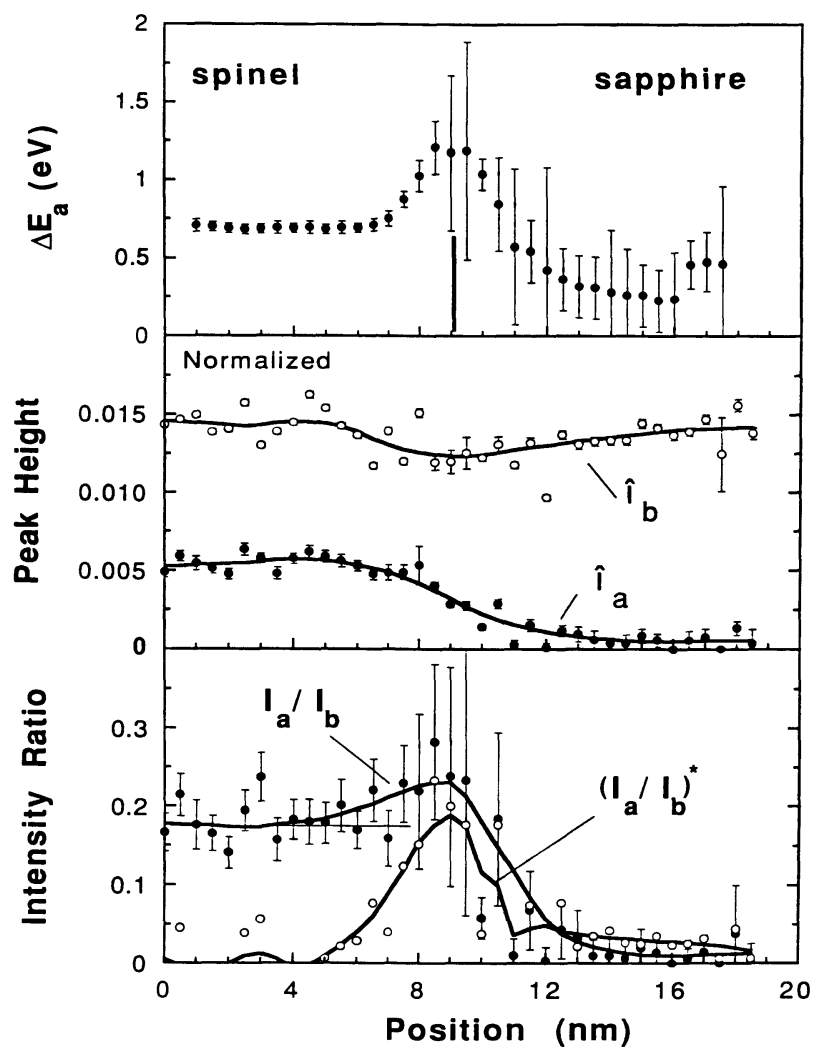

Fig. 8. - Line profiles derived by quantitative fitting of 2 Gaussians of variable width and height to the peaks a and $\mathrm{b}$ at the $\mathrm{Al} L_{2,3}$ edge threshold. The width of peak-a increases at the boundary, probably due to lattice strain. The ratio $I_{\mathrm{a}} / I_{\mathrm{b}}$ increases at the interface, over the same region that the composition varies. This provides a picture of $\mathrm{Al}$ site inversion in the space charge layer.

interface. There are no systematic chemical shifts observed across the interface, other than a $1 \mathrm{eV}$ shift of the $L$ edge onset in spinel $(78 \mathrm{eV})$ relative to the sapphire onset at $(79 \mathrm{eV})$. A downward shift of the "octahedral" peak b from spinel to sapphire is attributed to changes in the exciton binding energy [72, 74]. How this effect varies across the interface has not yet been investigated. Any band bending due to interfacial charge distributions will not be visible because of similar bending of both the core and conduction bands. No defect or interface states could be observed within the band-gap region. Such states might have been evident if a concentration of dangling bonds or vacancy defects were present.

\section{Discussion}

We begin the discussion by considering the interfacial chemical distributions and how they might affect the space charge region. To guide the discussion a schematic of the possible elemental distribution at the interface is illustrated in Figure 9, but this should not be taken to represent the actual distributions which are convoluted into the measured profiles. The profiles in Figure 7 suggest that the $\mathrm{Cr}$ content increases relative to $\mathrm{Al}$ at the boundary. $\mathrm{The} \mathrm{Cr} / \mathrm{Al}$ atomic ratio rises to 
a maximum peak height of 0.1 with $90 \%$ of this distribution within a width of $5 \mathrm{~nm}$ (assuming a normal distribution). Without knowledge of the Cr's real distribution it is assumed that the $\mathrm{Cr}$ is segregated to the interface and that the observed width reflects a rough or tilted boundary. It is noted that the spatial distribution is not required for the purpose of a quantitative compositional analysis and determination of the the electrostatic charge balance. Of course, the atomic structure and mechanical properties of the boundary will depend strongly on the details of the elemental distributions. The effect of beam broadening will spread the measured profile but for a foil thickness of about $50 \mathrm{~nm}$ the finite spectrometer entrance aperture collects only those scattering events occurring within about $0.8 \mathrm{~nm}$ of the probe position. If we further assume the $\mathrm{Al}$ atomic density is uniform up to and across the interface, the amount of $\mathrm{Cr}$ segregated to the interface is given by the integral of its distribution in Figure 7. In making this assumption we neglect the 11 at.\% increase in $\mathrm{Al}$ in the sapphire with respect to spinel and any decrease in $\mathrm{Al}$ due to the presence of excess $\mathrm{Cr}$ and $\mathrm{Mg}$. To a rough approximation, we can assume the fractional coverage of the interface is given by the number of available cation sites occupied by Cr. Taking the cube or (400) plane as an example, there are 8 octahedral sites per unit cell. In normal stoichiometric spinel there are two formula units per (400) plane, thus 4 octahedral sites are occupied giving a fractional coverage of $1 / 2$. The (400) interplanar spacing is $0.2 \mathrm{~nm}$. If the integrated $\mathrm{Cr}$ content in Figure 7 were condensed into this narrow width, the $\mathrm{Cr} / \mathrm{Al}$ atomic ratio would increase to $0.1 \times(5 / 0.2)$ or about 2.5. Accordingly, Cr may occupy either 2.5 lattice planes in substitutional sites $\left(\mathrm{Cr}_{\mathrm{Al}}\right)$ or 1.25 monolayers, filling all 4 of the substitutional sites per unit cell plus the remaining interstitial sites which are charged, $\left(\mathrm{Cr}^{\prime \prime \prime}\right)^{i}$. An alternative would be for $\mathrm{Cr}$ to fill tetrahedral sites, though with excess $\mathrm{Mg}$ also present this option seems unlikely. These estimates will be a little higher or lower according to the actual density of the interface planes. Since $\mathrm{MgCr}_{2} \mathrm{O}_{4}$ spinel is completely soluble in magnesium aluminate spinel, the equivalent of 2 planes could be easily accomodated within the structure. Since $\mathrm{Cr}$ is isovalent with $\mathrm{Al}, \mathrm{Cr}$ accommodation within the substitutional sites is the most likely since such defects will not contribute directly to the space charge layer [9].

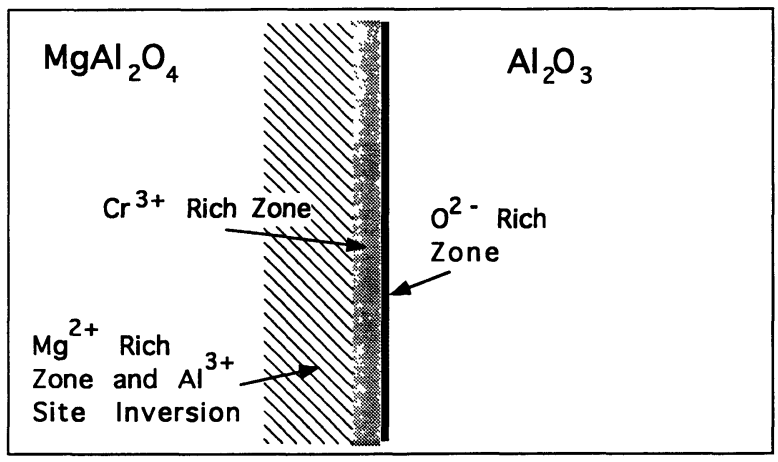

Fig. 9. - Schematic of segregation profile to illustrate a possible space-charge distribution model.

The excess $\mathrm{Mg}$ distribution is of similar shape and width as $\mathrm{Cr}$, and rises to a maximum peak intensity equal to 0.3 . There are 16 tetrahedral sites per unit cell area on the (400) plane of spinel, of which 2 are normally occupied, giving a fractional coverage of $1 / 8$. Following similar assumptions as before, we estimate an excess $\mathrm{Mg} / \mathrm{Al}$ of about $0.3 \times(5 / 0.2)$ or 7.5. The normal $\mathrm{Mg} / \mathrm{Al}$ ratio is 0.5 , therefore the results suggest that there is 15 times as much $\mathrm{Mg}$ or 30 atoms of $\mathrm{Mg}$ per unit cell 
area to be accommodated in the interfacial region. 5 of these could be accounted for by formation of the equivalent of 2.5 (400) layers of $\mathrm{MgCr}_{2} \mathrm{O}_{4}$ spinel. The remaining 25 amounts to about 1.5 fully occupied monolayers. By occupying interstitial sites, the excess $\mathrm{Mg}^{2+}$ leads to a surface charge density of $8 \times 10^{-18} \mathrm{C} / \mathrm{nm}^{2}$ which, if uncompensated by negatively charged species, would generate extremely high stresses of the order of $10^{6} \mathrm{MPa}$ (the tensile strength of sapphire is about $150 \mathrm{MPa}$ ). This charge density is too large for the system to be physically stable. The stress would be moderated somewhat if the excess $\mathrm{Mg}$ is distributed over the full $5 \mathrm{~nm}$ wide region. The local excess amounts to about a $20 \% \mathrm{Mg}$ per unit cell which may be organized by substitution for $\mathrm{Al}$ (i.e., $\mathrm{Mg}_{\mathrm{Al}}^{\bullet}$ ), and occupation of interstitial sites (i.e., $\mathrm{Mg}_{\mathrm{i}}^{\prime \prime}$ ). The driving force for accumulation of such large concentrations of $\mathrm{Mg}$ may be the attraction to a negatively charged fiber surface. A possible source of error which may account for an overestimation of Mg observation is poor background fitting. The $\mathrm{Mg} L_{2,3}$ is certainly difficult to extract from the intense background, however the systematic uniformity in the bulk spinel region of the profile gives confidence that the method used is stable. An underestimate of the $\mathrm{Al}$ content at the boundary may also result in the observed $\mathrm{Mg}$ excess. This option seems unlikely since beam spreading and overlap of sapphire will increase the apparent $\mathrm{Al}$ content. There was no evidence for preferential $\mathrm{Al}$ etching due to beam damage. This observation is in contrast to that made by Chiang et al. on the grain boundaries of various magnesium aluminate spinels $[10,11]$. The difference may lie in details of the electrostatic screening in the metal phase that occurs during nucleation of this spinel on the sapphire.

To avoid the large surface stresses, excess positive charge in the spinel must be balanced by an approximately equal amount of excess negative charge. Negatively charged defects in undoped spinel and sapphire include anion interstitials, cation vacancies, and cation site inversion. The $O$ profile in Figure 7 gives some insight into the $\mathrm{O}$ excess at the boundary. The O/Al has a peak maximum equal to about 0.5 . Following the same analysis as above for the (400) spinel plane, the $\mathrm{O}$ excess translates to 25 extra $\mathrm{O}^{2-}$ anions per unit cell. 20 of the 25 can be accounted for by the formation of 2.5 layers of $\mathrm{MgCr}_{2} \mathrm{O}_{4}$. The remaining 5 anions are probably segregated as interstitial charged defects at the interface. The site density for a monolayer of $O$ on the cube plane is 8 per unit cell area, which indicates that 0.6 monolayer of $\mathrm{O}^{2-}$ is present. A negative charge on the sapphire surface would compensate some of the charge carried by interstitial $\mathrm{Mg}^{2+}$. The remainder of the excess positive charge due to $\mathrm{Mg}$ build up could be compensated by creation of $\mathrm{Al}$ vacancies.

An estimate of the $\mathrm{Al}^{3+}$ site inversion is provided by the $\mathrm{Al} L_{2,3}$ near edge peak intensity ratio given by $\left(I_{\mathrm{a}} / I_{\mathrm{b}}\right)$ in Figure 8. Qualitatively, the increased ratio at the boundary indicates greater $\mathrm{Al}$ site inversion. The ratio increases from 0.18 in the bulk spinel phase to 0.28 at the boundary. Subtracting the spinel background ratio accentuates the interfacial increase. With reference to Figure 4 and the regression analysis, the measured $I_{\mathrm{a}} / I_{\mathrm{b}}$ ratios correspond to an inversion parameter of 0.1 , increasing to 0.3 at the interface. This suggests that an extra $10 \%$ of the $\mathrm{Al}$ ions occupy tetrahedral positions. Cation site exchange results in zero net charge creation, and therefore would not directly contribute to charge imbalance compensation. However, in the electric field created by the excess $\mathrm{O}^{2-}$ and $\mathrm{Mg}^{2+}$, redistribution of the inverted cations will take place. The $\mathrm{Mg}_{\mathrm{Al}}^{\bullet}$ will be attracted to the $\mathrm{Mg}_{\mathrm{i}}^{\prime \prime}$, and the $\mathrm{Al}_{\mathrm{i}}^{\prime \prime \prime}$ towards the $\mathrm{O}_{\mathrm{i}}^{\bullet \bullet}$. Confirmation of this effect awaits improved spatial resolution.

In the above discussion we have chosen to ignore variations in the $\mathrm{Al}$ density across the interface. Obviously this will modify slightly the estimates given, however, the description given above is meant only to provide a plausible picture of the elemental and defect site distributions. We have also ignored the possibility of aliovalent impurities, which are known to greatly influence space charge at very low concentration levels and we have made assumptions concerning interface structure. Greater insight will undoubtedly be obtained with a cleaner, more well defined system with 
a clearer picture of the atomic structure. In the future, it would be useful to examine the effect of substrate orientation and the role of oxygen partial pressure on the nature of the space charge region.

These measurements illustrate that a physically reasonable picture can be built up by quantitative analysis of spectrum-line profile data. Very large data sets can now be accumulated in very short times, putting stringent demands upon the speed and accuracy of data handling and processing. In this paper no attempt has been made to quantify or interpret the near edge structures on the $\mathrm{Mg} L_{2,3}$ and $\mathrm{K}$ and $\mathrm{Al} \mathrm{K}$ edges. Clearly further work is necessary to better understand the detailed near edge structures if they are to be used in this quantitative way, to extract electronic structure information of ceramic interfaces.

\section{Conclusions}

Spectrum-line profiles have been acquired across the interface between magnesium aluminate spinel and sapphire. The conventional integrated intensity line profiles provide a picture of the elemental distributions, whilst quantitative near edge structure analysis highlights electronic structure variations. Since the bonding in these oxides is highly localized, the near edge structure is able to provide information concerning the site symmetry of the cations. A set of standard spinels was used to generate an empirical relationship between edge intensity and spinel inversion parameter. A spectrum-line profile is analyzed to yield a picture of the $\mathrm{Al}$ site inversion across the interface. The principal observations of this investigation are that $\mathrm{Mg}$ and $\mathrm{Cr}$ segregate to the interface, accompanied by $\mathrm{Al}$ site inversion. A simple model is envisioned, whereby $\mathrm{O}^{2-}$ anions terminating on the surface of the substrate, influence the earliest stages of nucleation and growth. Interstitial $\mathrm{Mg}$ accumulates near the boundary under the influence of electrostatic attractive forces, $\mathrm{Cr}$ is attracted to the interface to minimize strain energy and the degree of site inversion is affected by the electric fields at the interface.

\section{Acknowledgements}

We wish to thank R. French of DuPont Research Center, Wilmington DE, and R. Raj of Cornell University, Ithaca N.Y., for providing the spinel standards and C.C. Bampton and J.R. Porter of Rockwell International, Thousand Oaks CA, for the provision of the transient liquid phase bonded composite. G. Duscher of the Max-Plank-Institut für Metallforschung, Stuttgart and M. Tencé of the Université Paris-Sud, Orsay Paris, are achnowledged for the supply of their custom functions that enable the spectrum-line profile acquisition. The research was supported through NSF grants DMR 9111839 and DMR 930625.

\section{References}

[1] Lewis M.H. and Murthy V.S.R., Compos. Sci. Technol. 42 (1991) 221.

[2] Coble R.L., J. Appl. Phys. 34 (1963) 1679.

[3] Rühle M. and Evans A.G., Mater. Sci. Eng. A 107 (1989) 187.

[4] Venkatachari K.R. and Raj R., J. Am. Ceram. Soc. 69 (1986) 135.

[5] Wang H.F., Gerberich W.W. and Skowronek C.J., Acta Metall. Mater. 41 (1993) 2425.

[6] Wang N., Wang Z. and Weatherly G.C., Metall. Trans. A 23A (1992) 1423.

[7] Molins R. and Bartout J.D., Coll. Phys. C1 51 (1990) 891. 
[8] Weinrauch D.A., J. Mater. Res. 3 (1988) 729.

[9] Yan M.F., Cannon R.M. and Bowen H.K., J. Appl. Phys. 54 (1983) 764.

[10] Chiang Y.-M. and Peng C.J., Adv. Cer. 23 (1987) 361.

[11] Chiang Y.-M. and Kingery W.D., J. Am. Ceram. Soc. 73 (1990) 1153.

[12] Carter G.B. and Morrissey K.J., LAdv. Cer. 12 (1984) 303.

[13] Carter C.B. and Schmalzried H., Phil. Mag. A 52 (1985) 207.

[14] Carter C.B. and Rasmussen Y.K., Acta Metall. Matr. 42 (1994) 2741.

[15] Carter C.B. and Rasmussen Y.K., Acta Metall. Mater. 42 (1994) 2729.

[16] Höche T., Kenway P.R., Kleebe H.J., Rühle M. and Morris P.A., J. Am. Ceram. Soc. 77 (1994) 339.

[17] Merkle K. L. and Smith D.J., Phys. Rev. Lett. 59 (1987) 2887.

[18] Sun C.P. and Balluffi R.W., Scripta Metall. 13 (1979) 757.

[19] Sunitzky D.W. and Carter C.B., J. Am. Ceram. Soc. 73 (1990) 2485.

[20] Li D.X., Pirouz P., Heuer A.H., Yadavalli S. and Flynn C.P., Phil. Mag. A 65 (1992) 403.

[21] Bruley J., Micrasc., Microanal., Microstruct. 4 (1993) 23.

[22] Bruley J., Höche T., Kleebe H.J. and Rühle M., J. Am. Ceram. Soc. 77 (1994) 2273.

[23] Navrotsky A. and Kleppa O.J., J. Inorg. Nucl. Chem. 29 (1967) 2701.

[24] Wood B.J., Kirkpatrick R.J. and Montez, Amer. Mineralogist 71 (1986) 999.

[25] Gobbi G.C., Christofferson R., Otten M.T., Miner B., Buseck P.R., Kennedy G.J. and Fyfe C.A., Chem. Letts. 6 (1985) 771.

[26] Navrotsky A., Wechsler B.A., Geisinger K. and Seifert F., J. Am. Ceram. Soc. 69 (1986) 418.

[27] Jayaram V. and Levi C.G., Acta Metall. 37 (1989) 569.

[28] Schmocker U., Boesch H.R. and Waldner F., Phys. Letts. 40A (1972) 237.

[29] Schmocker U. and Waldner F., J. Phys. C: Solid State Phys. 9 (1976) L235.

[30] Rouse K.D., Thomas M.W. and Willis B.T.M., J. Phys. C: Solid State Phys. 9 (1976) L231.

[31] Heuer A.H. and Mitchell T.E., J. Phys. C: Solid State Phys. 8 (1975) L541.

[32] Grimes N.W., Thompson P. and Kay H.F., Proc. Roy. Soc. (Lond.) A 386 (1983) 333.

[33] Mishra R.K. and Thomas G., Acta Cryst. A 33 (1977) 678.

[34] Hallstedt B., J. Am. Ceram. Soc. 75 (1992) 1497.

[35] Kingery W.D., Bowen H.K. and Uhlmann D.R., in Introduction to Ceramics. 2nd. ed., John Wiley and Sons: New York 4 (1976) p. 125.

[36] Dupree R., Lewis M.H. and Smith M.E., Phil. Mag. A 53 (1986) L17.

[37] Grimes R.W., J. Am. Ceram. Soc. 77 (1994) 378.

[38] Bianconi A., Bachrach R.Z., Hagstrom S.B.M. and Flodström S.A., Phys. Rev. B 19 (1979) 2837.

[39] Bursill L.A. and Lin P.J., Phil. Mag. 60 (1989) 307.

[40] Huang X.Y., Mader W. and Kirchheim R., Acta Metall. Mater. 39 (1991) 893.

[41] Knauss D. and Mader W., Ultramicroscopy 37 (1991) 247.

[42] Baik S., Fowler D.E., Blakely J.M. and Raj R., J. Am. Ceram. Soc. 68 (1985) 281.

[43] Trumble K.P. and Rühle M., in Metal-Ceramic Interfaces, M. Rühle et al., Ed. Pergamon Press: New York (1989) p. 144.

[44] Bruley J., Brydson R., Müllejans H., Meyer J., Gutekunst G., Knauss M.W.D. and Rühle M., J. Mater. Res. 9 (1994) 2574.

[45] Gautier M., Renaud G., Van L.P., Villette B., Pollak M., Thromat N., Jollet F. and Duraud J.P., J. Am. Ceram. Soc. 77 (1994) 323.

[46] Finnis M.W., Acta Metall. Mater. 40 (1992) S25.

[47] Duffy D.M., Harding J.H. and Stoneham A.M., Acta Metall. Mater. 40 (1992) S11.

[48] Taftø J. and Zhu J., Ultramicroscopy 9 (1982) 349.

[49] Brydson R., Sauer H., Engel W., Thomas J.M. and Zeitler E., J. Chem. Soc. Chem. Commun. 15 (1989) 1010.

[50] Brydson R., EMSA Bulletin 21 (1991) 57.

[51] Brydson R., Sauer H., Engel W. and Zeitler E., Microsc. Microanal. Microstr. 2 (1991) 159.

[52] Brydson R., Garvie L.A.J., Craven A.J., Sauer H. and Hofer F., J. Phys.: Condens. Matter 5 (1993) 9379.

[53] Hansen P.L., McComb D.W., Brydson R. and Richardson I., private communication.

[54] McComb D.W., Brydson R. and Hansen P.L., J. Phys.: Condens. Matter 4 (1993) 8363.

[55] Brytov I.A. and Romaschenko Y.N., Sov. Phys. Solid State 20 (1978) 384.

[56] Taft $\varnothing$ J. and Krivanek O.L., Phys. Rev. Lett. 48 (1982) 560.

[57] Taftø J., Nuc. Inst. Meth. Phys. Res. B 2 (1984) 733.

[58] Krivanek O.L., Disko M.M., Taftø J. and Spence J.C.H., Ultramicroscopy 9 (1982) 249. 
[59] Spence J.C.H., Krivanek O., Taftø J. and Disko M., in EMAG (1982) Institute of Physics.

[60] Tafto J., J. Appl. Crystallogr. 15 (1982) 378.

[61] Qian W., Tötdal B., Hoier R. and Spence J.C.H., Ultramicroscopy 41 (1992) 147.

[62] Zhang S.-Y. and Cowley J.M., Thin Solid Films 148 (1987) 3011.

[63] Tanaka I., Kawai J. and Adachi H., Phys. Rev. B Submitted (1994).

[64] Xu Y.-N. and Ching W.Y., Phys. Rev. B 43 (1991) 4461.

[65] Abramov V.N., Karin M.G., Kuznetsov A.I. and Sidorin K.K., Sov. Phys. Solid State 21 (1979) 47.

[66] Batra I.P., J. Phys. C. (Solid State Phys.) 15 (1982) 5399.

[67] Ciraci S. and Batra I.P., Phys. Rev. B 28 (1983) 982.

[68] Shangda X., Chandxin G., Libin L. and Ellis D.E., Phys. Rev. B 35 (1987) 7671.

[69] Guo J., Ellis D.E. and Lam D.J., Phys. Rev. B 45 (1992) 13647.

[70] Tossell J.A., J. Phys. Chem. Sol. 36 (1975) 1273.

[71] Tossell J.A., J. Am. Ceram. Soc. 97 (1975) 4840.

[72] Balzorotti A., Antonangeli F., Girlanda R. and Martino, Phys. Rev. B 29 (1984) 5903.

[73] Hong S.Y., Anderson A.B. and Smialek J.L.., Surf. Sci. 230 (1990) 175.

[74] Balzorotti A., Antonangeli F., Girlanda R. and Martino G., Solid State Comm. 44 (1982) 275.

[75] Pantelides S.T. and Harrison W.A., Phys. Rev. B 13 (1976) 2667. 